\title{
Open Cholecystectomy Under Thoracic Epidural Block - A Case Report
}

\author{
Asim B Mohammad* \\ University of Lahore Medical School, Social Security Hospital, Multan Road, \\ Lahore, Pakistan \\ *Corresponding Author: Asim B Mohammad, University of Lahore Medical School, \\ Social Security Hospital, Multan Road, Lahore, Pakistan.
}

Received: October 08, 2020

Published: December 08, 2020

(C) All rights are reserved by Asim B

Mohammad.

\section{Abstract}

We present a clinical case of a 37-year-old housewife of Pakistani origin, who presented with right hypochondrial pain. Ultrasound analysis of her abdomen revealed cholelithiasis and the decision for an elective cholecystectomy was taken. The patient refused general anaesthetic due to fear that she may not regain consciousness, therefore thoracic (T6-T7) epidural block was offered. Following a review of published literature, we believe this to be the first reported case of open cholecystectomy under thoracic epidural block, for reasons of patient choice. The procedure was a success and the patient was discharged with no further incident.

Keywords: Case Report; Open Cholecystectomy; Thoracic Epidural Block; Fear; Anaesthetic

\section{Introduction}

Laparoscopic cholecystectomy is the gold standard for the management of cholelithiasis, due to the obvious minimally invasive procedure, associated with less pain and a shorter recovery period. In developing countries such as Pakistan, laparoscopic surgeries may not be feasible for reasons of lack of local expertise, economic resources, or both [1] and open cholecystectomy is necessary.

Traditionally, laparoscopic cholecystectomy is carried out under general anaesthesia. However, in poor candidates for general anaesthesia [2] regional anaesthesia is also successfully used today [3]. However, in all other reported cases of planned open cholecystectomy has been carried out exclusively under general anaesthesia. To our knowledge, our successful procedure of planned open cholecystectomy under thoracic epidural block is unique.

\section{Case Report}

The 37-year-old female housewife of lower-class Pakistani heritage presented with intermittent right hypochondrial pain, which had lasted eight weeks. She had been managed on oral analgesics but the pain persisted. Ultrasound analysis of her abdomen revealed cholelithiasis and the decision for an elective cholecystectomy was taken. The patient refused general anaesthetic due to fear that she may not regain consciousness, caused by peer group misinformation regarding anaesthesia. Other than her specific anxiety relating to general anaesthesia, which she had not previously experienced, her psychological state was unremarkable, she had no known allergies or previous surgeries. Despite receiving recommended counselling on the risks of general anaesthesia, she continued to refuse. The patient was consulted for mild sedation, regional thoracic T6T7 epidural block anaesthesia and surgery, for which she verbally consented. It was also explained to the patient that, in the case of a medical emergency, for her safety, it may be necessary for a general anaesthesia. A pre-operative assessment reported; blood pressure $110 / 70$, heart rate $80 \mathrm{bpm}$, temperature $98^{\circ} \mathrm{F}\left(36.6^{\circ} \mathrm{C}\right)$, oxygen saturation 96-97\%, respiratory rate 17 breaths per minute, blood workups were within normal range and normal spine morphology, body mass index was not recorded. Echocardiogram revealed mild mitral stenosis, although the patient was asymptomatic. Pre-operatively the patient was prescribed oral anxiolysis dormicum (7.5 
$\mathrm{mg}$ ) overnight. She was transferred to theatre the following morning after checking her vital signs.

In theatre, standard II monitoring was applied; oxygenation, ventilation, circulation and temperature were continually monitored. The patient was prepared for intravenous access via an 18 gauge cannula prior to the epidural. An 18 gauge epidural catheter was passed at the T6-T7 interspace in a sitting position and fixed. The patient was moved to a supine position. The level of the block was checked between T4-T10 by injecting a test dose of xylocaine $2 \%(3 \mathrm{ml})$ to exclude intra-thecal or intravascular placement. Vital signs and respiration rate remained normal after the dose. Full dose for the local anaesthetic bupivacaine $(0.5 \%, 5 \mathrm{ml})$ was given, as this was the only local anaesthetic available at that time. The cholecystectomy surgical procedure started 10 minutes after the dose, conducted by a consultant grade surgeon. The patient tolerated the surgical incision well. During the procedure the patient was given oxygen with a nasal cannula and sedated mildly with midazolam $2 \mathrm{mg}$ intravenously, to alleviate her anxiety of the theatre and surgical environment.

After 40 minutes, the patient experienced mild discomfort and was given an additional $3 \mathrm{ml}$ of bupivacaine $0.25 \%$. The patient tolerated the open cholecystectomy well during the 70 minute, uneventful procedure. The patient remained haemodynamically stable throughout and was moved to the recovery suite where she received bupivacaine infusion $0.1 \%$ for 12 hours. She was then switched to oral analgesics. The epidural catheter was removed the following day. The procedure was a success and the patient was discharged to the cardiology team for follow-up of the mitral stenosis. There was no reported further incident arising from the cholecystectomy and the thoracic block procedure.

\section{Discussion}

Few, if any, statistical data are available on the number of patients who refuse general anaesthetic (GA) for surgical procedures, or whether there is a cultural, socio-economic influence. For many surgical procedures, regional anaesthesia (RA) can be an alternative. Advances in techniques for RA have simplified and improved safety with the introduction of ultrasound-guided techniques. New long-acting local anaesthetics have provided an opportunity to explore novel approaches to RA [4].

Cases where RA has been used for open upper abdominal surgery, have been reported but these usually refer to patients who are poor candidates for general anaesthesia, for example, those with limited respiratory function where non-invasive ventilation is necessary [5]. Not, as in this case, for reasons of patient refusal.

In high-income countries laparoscopic cholecystectomy (LC) is the first-line surgical choice in cholelithiasis disease, due to shorter hospital stays, reduced mortality and morbidity, reduced cardiac and respiratory complications [6] and its cost-effective benefits [7]. However, in low-income countries, the low caseload and high investment costs mean that laparoscopy is often a higher economic burden than open cholecystectomy [7]. Such as this case in Pakistan, surgical expertise is not always available. Another economic consideration is the cost-benefit considerations between regional versus general anaesthetic. Decreased cost, operating room expenses, postoperative resources and length of stay, is also an economical benefit of utilising RA, over GA [8].

While cholecystectomy is a common surgery, with rare postoperative complications, 'post-cholecystectomy syndrome' (PCS) is a well-recognised consequence [9]. Symptoms appear between 1 week and 6 months after surgery. Few patients have a detectable cause for symptoms and therefore it is difficult to predict its occurrence. Emergency physicians should be aware that patients who have undergone previous cholecystectomy, may present with symptoms of biliary colic, and they should not exclude the possibility of remnant gallbladder pathologies.

A meta-analysis conducted by Guo et al., suggest cholecystectomy and cholecystolithiasis may be involved in the development of liver cancer, especially for intrahepatic cholangiocarcinoma (ICC) although, they acknowledge that most studies were case-control studies and short-term cohort studies and that long-term cohort studies should be conducted, the report stressed the importance of continued follow-up of these patients [10]. One limitation of this case report is the lack of patient follow up.

This case report, emphasizes important aspects of this open cholecystectomy surgery under T6-T7 epidural block, where the patient's refusal for GA and the lack of facilities for LC have contributed to the unique nature of this successfully treated case.

\section{Conclusion}

In conclusion and following an extensive review of the published literature, we believe this to be the first reported case of successful elective open cholecystectomy under thoracic epidural block. This 
is an important case to present, where there is significant patient fear regarding the general anaesthetic procedure, and also where it is necessary to conduct open cholecystectomy surgery, should resources for a laparoscopic procedure make it unfeasible, for reasons of cost or expertise.

\section{Acknowledgements}

"The authors thank Heather L. Mason of Coufetery Comms for providing medical writing support [literature review, manuscript writing], which was funded independently by Dr. M. Asim, Tipperary, Republic of Ireland in accordance with Good Publication Practice (GPP3) guidelines (http://www.ismpp.org/gpp3)".

\section{Bibliography}

1. Ishaq H., et al. "Pediatric laparoscopic surgery; initial experience from Pakistan; first 100 cases in single center". Journal of Pakistan Medical Association 66.10 (2016): S116-S118.

2. Bilgi M., et al. "Experience of Laparoscopic Cholecystectomy Under Thoracic Epidural Anaesthesia: Retrospective Analysis of 96 Patients". Turkish Journal of Anaesthesiology and Reanimation 43.1 (2015): 29-34.

3. Jae-Woo Y., et al. "Laparoscopic cholecystectomy performed under regional anesthesia in a patient who had undergone pneumonectomy". Korean Journal of Anaesthesiology 56.3 (2009): 330-333.

4. Wahal C., et al. "Advances in regional anaesthesia: A review of current practice, newer techniques and outcomes". Indian Journal of Anaesthesia 62.2 (2018): 94-102.

5. Yurtlu BS., et al. "Non-invasive mechanical ventilation and epidural anesthesia for an emergency open cholecystectomy". Brazilian Journal of Anaesthesia 66.5 (2016): 546-548.

6. Antoniou SA., et al. "Meta-analysis of laparoscopic vs open cholecystectomy in elderly patients". World Journal of Gastroenterology 20.46 (2014): 17626-17634.

7. Silverstein A., et al. "Laparoscopic versus open cholecystectomy: A Cost-Effectiveness Analysis at Rwanda Military Hospital". World Journal of Surgery 41.5 (2017): 1225-1233.

8. Siu A., et al. "A Cost Analysis of Regional Versus General Anaesthesia for Carotid Endarterectomy". Annuals of Vascular Surgery 39 (2017): 189-194.

9. Arora D., et al. "Post-cholecystectomy syndrome: A new look at an old problem". Journal of Minimal Access Surgery 14.3 (2018): 202-207.
10. Guo L., et al. "Cholelithiasis, cholecystectomy and risk of hepatocellular carcinoma: a meta-analysis". Journal of Cancer Research and Therapeutic 10.4 (2014): 834-838.

\section{Assets from publication with us}

- Prompt Acknowledgement after receiving the article

- Thorough Double blinded peer review

- Rapid Publication

- Issue of Publication Certificate

- High visibility of your Published work

Website: www.actascientific.com/

Submit Article: www.actascientific.com/submission.php

Email us: editor@actascientific.com

Contact us: +919182824667 